\title{
PEMILIHAN GAYA BELAJAR VARK UNTUK MENINGKATKAN KEAKTIFAN SISWA DALAM PEMBELAJARAN BAHASA INDONESIA
}

\author{
${ }^{1}$ Asih Riyanti dan ${ }^{2}$ Sungkono \\ ${ }^{1}$ Pendidikan Bahasa Indonesia, Universitas Borneo Tarakan, Indonesia \\ email: asihriyanti17@gmail.com \\ ${ }^{2}$ Pendidikan Bahasa Indonesia, Universitas Borneo Tarakan, Indonesia \\ email: sungkono@borneo.ac.id
}

\begin{abstract}
ABSTRAK
Setiap keberhasilan dalam proses pembelajaran akan dipengaruhi bermacam faktor dari lingkungan, sekolah, sikap, ataupun siswa itu sendiri. Setiap siswa mengalami pekembangan kognitif, afektif, dan psikomotorik. Perkembangan siswa memiliki keunikan dan karakter masing-masing dalam proses pembelajaran untuk merespon dan memahami materi ajar atau informasi yang diperolehnya. Kemadirian belajar siswa dapat dilihat dari capaian siswa dalam merespon, memahami, dan mengolah informasi serta menyelesaikan berbagai tugas. Setiap siswa memiliki gaya belajar yang mononjol dalam dirinya, dan guru harus dapat mengakomodasinya. Hal itu untuk mencapai tujuan pembelajaran dengan baik dan efektif. Gaya belajar merupakan kunci keberhasilan siswa dalam belajar. Ada model (type) gaya belajar (Fleming, 2001) yaitu VARK (Visual, auditory, Reading, Kinesthetic) yang dapat meningkatkan keaktifan siswa dalam pembelajaran bahasa Indonesia. Siswa dapat belajar melalui indera yang dimilikinya yaitu dengan gaya belajar visual ialah belajar atas apa yang dilihat, siswa dengan gaya belajar auditorial yaitu belajar melalui apa yang didengar, dilihat, dan secara kinestetik yakni belajar melalui gerak dan sentuhan.
\end{abstract}

Kata kunci: Gaya Belajar VARK, Keaktifan Siswa, Pembelajaran Bahasa Indonesia

\begin{abstract}
Every success in the learning process will affect environmental factors, schools, attitudes, or students themselves. Each student enhances cognitive, affective, and psychomotor development. Student trading has the uniqueness and character of each in the learning process to respond to and understand teaching material or information obtained. Student learning independence can be seen from the achievements of students in responding, solving, and processing information by completing various tasks. Every student has a learning style that is prominent in him, and the teacher must be able to accommodate it. That is to achieve the learning objectives well and effectively. Learning style is the key to student success in learning. There are models (type) of learning styles (Fleming, 2001), is VARK (Visual, auditory, Reading, Kinesthetic) that can increase student activity in learning Indonesian. Students can learn through the senses that they have with a visual learning style that learns from what is seen, students with an auditory learning style that is learning through what is heard, and a kinesthetic learning style that is learning through motion and opening.
\end{abstract}

Keywords: learning style, VARK, Student Activity, Indonesian Language Learning

DOI: https://doi.org/10.31943/bi.v5i1.62

How to Cite: Riyanti, A., \& Sungkono. (2020). Pemilihan Gaya Belajar untuk Meningkatkan Keaktifan Siswa dalam Pembelajaran Bahasa Indonesia. Bahtera Indonesia; Jurnal Penelitian Bahasa Dan Sastra Indonesia , 5(1), 27-36. https://doi.org/10.31943/bi.v5i1.62 


\section{PENDAHULUAN}

Pembelajaran Bahasa Indonesia menjadi salah satu mata pelajaran di semua tingkat pendidikan. Di perguruan tinggi pun diberikan sebagai mata kuliah wajib yang harus ditempuh oleh mahasiswa. Tujuan dari adanya pendidikan belajar bahasa Indonesia ialah siswa ataupun mahasiswa mampu berkomunikasi dengan baik yakni komunikasi lisan maupun tulis. Dalam kehidupan seharihari komunikasi lisan tidak dapat dielakkan lagi karena manusia tidak akan mampu menghitung berapa jumlah kata yang diucapkan dalam waktu satu jam atau bahkan satu hari. Manusia dalam kehidupan seharihari berinteraksi dengan manusia yang lain dan menggunakan bahasa yang sifatnya sangat kompleks.

Peningkatan bentuk komunikasi ini menjadi hal penting untuk terus diperhatikan dalam diri siswa. Dalam dunia pendidikan seorang guru dapat memperhatikan siswa di kelas pada saat pembelajaran melalui interaksi antara siswa dengan siswa dan antara siswa dengan guru. Guru harus profesional sebagai pendidik. Guru dapat menggunakan media, pendekatan, metode, strategi, ataupun gaya belajar tertentu agar dapat memunculkan dan menarik siswa untuk aktif di kelas. Namun, kenyataannya seringkali siswa di kelas hanya diam ketika guru sedang menjelaskan materi pembelajaran. Apabila guru memberikan penugasan kelompok ataupun presentasi di kelas, maka masih seringkali terlihat siswa yang hanya diam, pasif dan tanpa menunjukkan keaktifan dirinya di dalam proses pembelajaran.

Salah satu yang sangat berpengaruh terhadap hasil belajar ialah gaya belajar. Setiap siswa memiliki gaya belajar yang berbeda-beda yang harus diketahui oleh guru. Oleh sebab itulah, setiap siswa pun juga harus mampu mengenali gaya belajarnya sendiri sehingga mudah untuk menerima materi pembelajaran. Apabila guru telah mengetahui gaya belajar setiap siswa, maka dapat disiapkan strategi yang sesuai dengan apa yang akan diajarkan sehingga proses belajar menjadi lebih baik.

Gaya belajar dapat dikatakan sebagai cara atau bentuk belajar yang dilakukan oleh siswa yang paling digemari yang tentu berbeda dari yang lain. Itulah yang menjadi keunikan dari setiap siswa. Gaya belajar yang disukai oleh siswa ini berasal dari pribadi siswa tersebut dan di dalamnya termasuk psikologisnya, sosio kultural, latar belakang kehidupan, pengalaman pendidikan, dan kemampuan kognitifnya. Gaya belajar adalah cara untuk mengenali beragam metode belajar yang disenangi siswa agar belajar siswa lebih efektif. Oleh akrena itu dapat dikatakan jika ingin hasil belajar baik dan pembelajaran 
dengan mudah diterima oleh siswa maka harus mengerti gaya belajarnya.

Melalui gaya belajar maka siswa akan lebih nyaman belajar dengan melakukan kegiatan berpikir dan memproses informasi. Ada penelitian tentang gaya belajar yakni dilakukan oleh Ezzeldin (2017) yang kemudian didapatkan kesimpulan bahwa meskipun berbagai studi telah mengaitkan dengan gaya belajar dengan kinarja, maka ada saja kendala secara kognitif yang dapat menyebabkan siswa mengabaikan tentang pengetahuannya. Berdasarakan hasil penelitiannya disampaikan bahwa ketika siswa disajikan materi ajar yang sesuai dengan gaya belajar yang disenangi oleh siswa, maka beban kognitif atau mental siswa akan lebih baik dibanding mengajar dengan tanpa menyesuaikan dengan gaya belajar siswa.

Dalam pembelajaran bahasa Indonesia dibutuhkan pemahaman guru terhadap gaya belajar siswa. Hal itu dikarenakan gaya belajar dapat menentukan seorang individu berinteraksi dan bereaksi dalam lingkungan beljar, mencerminakan preferensi dirinya yang sesungguhnya (Dorça, Araújo, de Carvalho, Resende, \& Cattelan, 2016). Suatu Gaya belajar dapat menjadikan siswa lebih aktif dalam proses pembelajaran. Tuntutan dari pelaksaan pembejaran oleh guru dan siswa ialah terjadi adanya respon yang baik dan siswa antusias dalam kegiatan pembelajaran. Siwa memiliki sikap yang aktif dalam proses pembelajara menjadi salah satu tujuan pembelajaran. Siswa bukan sebagai objek yang diberika materi dengan mendengarkan ceramah guru, namun guru harus mampu menumbuhkembangkan sikap aktif dan kreatif siswa. Aktif dalam bertanya, aktif dalam mengerjakan tugas, dan aktif berinteraksi dengan teman sejawat atau dengan guru.

Usaha menumbuhkembangkan keaktifan siswa dalam pembelajaran bahasa Indonesia, maka guru dapat memilih gaya belajar yang sesuai dengan tujuan pembelajaran dan karakteristik siswa sesuai dengan latar belakang siswa. Hal ini dikarenakan keaktifan siswa menjadi penting dalam diri siswa karena ini dapat memicu tumbuhkembangnya sikap disiplin, berpikir kritis, logis, dan bersaing yang positif.

\section{METODE PENELITIAN}

Metode yang digunakan dalam kajian ini ialah studi pustaka. Artikel ini disusun melalui telaah berbagai buku, artikel sejenis, dan bermacam referensi yang berkitan dengan gaya belajar dan keaktifaan siswa dalam pembelajaran bahasa Indonesia. Telaah terhadap penelitian sejenis juga dilakukan guna memperoleh kesimpulan yang sahih. 


\section{HASIL DAN PEMBAHASAN}

\section{Gaya Belajar}

Pendidikan menjadi hal penting bagi setiap individu untuk kemajuan diri. Melalui pendidikan siswa dapat belajar dengan tersistem dan mencapai tujuan yang diharapkan. Dalam proses pembelajaran maka siswa akan mengalami proses perkembangan dalam dirinya. Sebagai makhluk sosial maka siswa harus siap fisik dan mental ketika nantinya akan berada di masyarakat dengan mengaplikasikan ilmu yang telah dimilikinya. Siswa harus siap menghadapi tantangan dunia dengan menjadi sumber daya manusia yang berkualitas. Hal ini dapat diperoleh melalui pendidikan.

Salah satu yang ada dalam pendidikan ialah adanya guru dan siswa yang saling berinteraksi. Setiap siswa memilki karaketeristik yang berbeda antara siswa yang satu dengan siswa yang lainnya (Siki, 2019). Guru harus tanggap terhadap perkembangan dan perubahan diri siswa. Sementara siswa harus mampu menerima dan mengolah materi atau informasi yang diperolehnya. Guna memaksimalkan proses pembelajaran, guru harus dapat mengenali gaya belajar setiap siswa. Gaya belajar siswa yang satu dengan siswa yang lain tidak sama. Setiap individu dapat dikatakan mempunyai empat gaya belajar, namun gaya belajar akan dapat diketahui dominan dan tidak dominan (Aydın, 2015). Struktur pembelajaran sangat beragam dan kompleks. Ini memunculkan siswa memiliki gaya belajar yang memungkinkan memproses kemungkinankemungkinan yang ada dan akan terjadi. Ada model yang dapat menentukan siswa dalam memproses pembelajaran yaitu: pengalaman langsung dan nyata, konseptualisasi yang abstrak, observasi reflektif, dan eksperiman (Kolb, 2015). Sementara itu, adaya belajar dan mengajar dapat dikatakan sebagai suatu komponen penting dalam proses belajar mengajar (Alnujaidi, 2018). Seseorang yang memeroleh informasi dalam tahap konseptual asbtrak tentu akan mencoba ide dan pemikirannya. Hal yang difokuskan ialah menyukai situasi yang memiliki jawaban yang benar dan pemecahan masalah. Konseptual abstrak ini diperoleh dari seseorang yang memeroleh informasi sehingga membentuk tahap observasi.

Sementara itu ada pula pendapat lain mengenai model gaya belajar. Terdapat model gaya belajar (Silverman \& Forum, 1992) bahwa terdiri dari jawaban atas empat pertanyaan yaitu: (1) jenis informasi yang disenangi oleh siswa secara sensorik (pemandangan, fisik, suara) atau sebagai intuitif (pikiran, ingatan dan wawasan); (2) jenis sensorik yang efektif dirasakan yaitu berupa gambar, tabel, diagram, atau berupa 
verbal yakni penjelasan lisan dan tertulis; (3) bagaimana siswa lebih senang dalam memproses suatu informasi: secara aktif (melalui keterlibatan diskusi atau fisik); dan (4) bagaimana siswa secara spesifik maju menuju pemahaman: berurutan secara logis, dan secara global. Adanya hal tersebut maka siswa akan lebih menyukai informasi yang konkret, fakta, dan pengulangan, seperti 1) mampu menyelesaikan masalah secara praktis, menyukai teori dan interpretasi, menemukan hubungan, dan cenderung konseptual. 2) Siswa akan menyukai gambar, tabel, diagram, serta mempu menjelaskan dengan benar. Secara verbal siswa lebih suka penjelasan lisan dan tertulis dari pada hanya sekadar ditampilkan. 3) siswa akan lebih aktif memproses informasi yang diperolehnya dan senang mencoba berbagai hal secara mandiri. 4) siswa berpikir logis, runtut, dan berfikir konvergen dalam memahami informasi. Hal tersebut dapat menajadi acuan guru dalam mengenali dan menentukan gaya belajar siswa dalam pembelajaran.

Bukan hanya gaya belajar dari segi siswa yang dapat meningkatkan keaktifan siswa selama pelaksanaan pembelajaran, Namun gaya belajar setiap guru juga dapat memengaruhi keaktifan siswa. Ada empat dimensi sebagai gaya pengajaran guru yang sesuai dengan tugasnya dengan pertanyaan sebagai berikut: (1) jenis informasi apa yang ditekankan oleh guru yaitu apakah abstrak atau konkret; (2) bagiamna model presentasi guru, apakah visual atau verbal; (3) bagaimana model partisipasi guru dalam memfasilitasi siswa dalam presentasi, apakah aktif atau pasif; dan (4) apa jenis perspektif yang disediakan untuk perkembangan siswa, apakah global dan relevansi atau konteks. Untuk menjawab pertanyaan tersebut maka diharapkan dapat menemukan jawaban yang ke depannya akan digunakan atau dilakukan dalam pelaksanaan pembelajaran.

Gaya belajar bukan hanya memengaruhi siswa merespon dan mencerna materi ajar, tetapi dapat meningkatkan motivasi dalam pembelajaran. Dalam buku Engaging School ditulis bahwa motivasi dapat ditingkatkan melalaui partisipasi aktif dan ini menjadikan kemajuan dalam akademik siswa (Medicine, 2004). Sebuah motivasi, prestasi, dan kinerja siswa akan dapat meningkat apabila gaya belajar siswa disesuaikan dengan gaya mengajar. Misalnya seorang siswa menyukai persepsi visual dengan menggunakan bagan, diagram, dan tabel, serta film. Ada enam tipe gaya belajar sebagai modalitas belajar (NA, 2013) yaitu visual, auditif, kinestetik, taktil, olfaktoris, dan gustatif. Gaya belajar yang berdasarkan pada indera manusia di mana cenderung berdasarkan apa yang dilihat, didengar, dan melalui sentuhan atau gerak. Ada tipe gaya 
belajar ada tiga yakni yaitu gaya belajar VARK (Visual, Adudotory, Reading, Kinestetic ialah gaya belajar yang menggunakan indera, di dalamnya membutuhkan kepekaan dan pemahaman dari Visual (yang dilihat), Auditory (yang didengar), Reading (dilihat/dibaca), dan Kinesthetic (yang disentuh atau yang bergerak) dari indera yang dimiliki oleh siswa (Fleming, 2001).

Gaya visual yakni siswa yang menggunakan indera yakni penglihatan seperti mengamati, menonton, membaca, dan menyaksikan. Adapun gaya auditori ialah siswa menggunkan dengan baik pendengaranya seperti menyimak, mendengarkan, dan bercakap. Sementara itu, kinestetik ialah siswa belajar dengan memanfaatkan lebih pada fisik dan emosinya, yang langsung dapat menggerakkan tubuh misalnya belajar di berbagai tempat, merasakan, dan mengoptimalkan rasa dan fisik untuk membentuk suatu tindakan.

Berdasarkan uraian di atas dapat disimpulkan gaya belajar merupakaan cara yang ditempuh individu untuk menerima dan mengolah informasi, memecahkan masalah dan dapat melalui indera yang dimiliki baik visual, auditori, dan kinestetik (VARK). Adapun faktor yang memengaruhi gaya belajar yakni dari faktor fisik, lingkungan, emosional, dan sosial individu itu sendiri.

\section{Keaktifan Siswa}

Keaktifan merupakan kegiatan yang melibatkan fisik dan mental untuk berbuat sesuatu. Keaktifan dapat dijumpai pada pembelajaran dan yang menjadi perhatian adalah keaktifan siswa pada kegiatan belajar mengajar. Keaktifan yang melibatkan kegiatan fisik berarti melibatkan anggota tubuh baik berbicara, menanya, mendengarkan, atau melihat. Melibatkan mental yakni sebuah keberanian yang muncul dalam diri ketika berinteraksi dengan orang lain. Keaktifan siswa dalam pembelajaran ini untuk mengontruksi pengetahuan, membangun pemahaman, dan membangun kondisi yang baik dalam pembelajaran.

Aktivitas belajar yang dilakukan oleh siswa dapat memengaruhi dan membaca perubahan ke arah yang lebih baik bagi diri siswa karena adanya saling berinteraksi antara siswa yang satu dengan yang lainnya. Setiap siswa bersaing dengan baik untuk pencapaian prestasi. Saling kompetitif sebagai kebutuhan diri siswa agar berhasil dan memenangkan suatu persaingan untuk peningkatan prestasi (Wijaya, 2015). Siswa akan memberikan balikan atas apa yang dilihat, didengar, dan dirasakannya. Sementara siswa yang lain memberikan pendapat dan akhirnya saling bertukar pendapat sesuai dengan potensi dan pengalaman yang telah didapatkan. 
Menciptakan keaktifan siswa di kelas dapat dilakukan dengan bertanya pada guru, menjawab, berpendapat, bekerja sama dalam tugas kelompok, diskusi dan mengomunikasikan hasil diskusinya. Dengan demikian palaksanaan kegiatan belajar mengajar tidak monton dan berpusat pada siswa. Suasana kelas menjadi lebih hidup dan menyenangkan. Memberikan kesempatan siswa memilih cara atau gaya belajarnya maka akan dapat menciptakan suasana belajar yang efektif, siswa aktif dan belajar yang menyenangkan (Entwistle, 1998). Keaktifan siswa dapat dibangun melalui respon dari guru yakni dengan gaya belajar tertentu sehingga siswa dapat mengontruksi pengetahuannya.

Dengan demikian dapat dikatakan bahwa keaktifan siswa merupakan kegiatan yang melibatkan fisik dan mental untuk berbuat baik menanya, berpendapat, dan tindakan lainnya yang melibatkan interaksi antara siswa dengan siswa dan siswa dnegan guru. Hal ini dapat dilihat dan hasil belajar setiap siswa yang tentu akan berbeda.

\section{Gaya Belajar dalam Pembelajaran Bahasa Indonesia}

Salah satu yang memengaruhi rendahnya hasil belajar ialah karena pembelajaran di sekolah masih berpusat pada guru. Sekolah sebagai bagian dari pusat pendidikan seharusnya mampu mengubah siswa menuju perubahan yang maju dan berdaya saing. Pendidikan sebagai proses yang memberikan pengetahuan dan keterampilan yang dibutuhkan manusia. Sekolah sebagai bagian dari demokrasi, yang berfungsi mencapai tujuan yang beragam (Çınar, 2019). Dalam hal ini dapat dilihat pada pembelajaran bahasa Indonesia yang bertujuan sebagaimana fungsi bahasa sebagaimana fungsinya yakni untuk berkomunikasi lisan dan tertulis.

Melalui pembelajran bahasa Indoensia, siswa diharapkan mempunyai kemampuan dalam menangkap makna dari pesan atau informasi yang diterima serta mampu menalar atas informasi tersebut (Tarnisih, 2019). Dalam pembelajaran bahasa Indonesia seorang guru harus memahami gaya bahasa yaang disenangi siswa. Guru harus memerhatikan emosional siswa dan persepsi sensorik yang dibuktikan melalui komunikasi verbal dan nonverbal (Vinyamata, 2011). Dalam pembelajaran bahasa Indoensia dapat menggunakan gaya bahasa VARK yang diusulkan oleh Fleming. Guru dapat memberikan pembelajaran sastra dengan gaya belajar VARK. Berdasarkan hasil survei sastra dapat berpengaruh sebagai materi ajar yang dapat membadingkan gaya belajar mengajar pada prestasi akademik siswa dalam belajarnya (García, 2007). Gaya belajar dapat memengaruhi siswa dalam 
berkompetisi dan berdampak positif pada hasil belajar siswa. Model VARK ini mengandaikan bahwa setiap siswa akan mampu mengidentifikasi gaya belajarnya sendiri dan menyadari preferensi inderawi yang dimilikinya. Pembelajan sastra melibatkan indera yang dimiliki oleh siswa baik penglihatan, pendengaran, ataupun rasa. Berbagai bentuk sastra puisi, drama, dan novel dapat dibaca yakni melibatkan penglihatan (visual) siswa, satra tersebut juga dapat (reading) dibaca dengan keras atau diperdengarkan (auditory), misalnya saja pembacaan puisi. Dari sastra itu pula siswa mampu menemukan hal-hal yang berkaitan dengan perasaan akibat dari pembacaan atau yang telah dibacanya (kinestetik). Melalui visualisasi, auditori, dan kinestetik inilah guru dapat melatih siswa menilai instruksi serta memberikan peluang langsung untuk siswa berkespresi dan berpendapat. Melalui kegiatan tersebut siswa akan mampu mengahsilkan karya baru, berpikir kritis, dan memecahkan masalah dalam kehidupan.

Bukan hanya dengan sastra yang diterapkan dalam pemeblaajran sastra mengguakan gaya belajar VARK untuk dapat meningkatkan keaktifan siswa. Namun beragam jenis media yang dapat dimanfaatkan untuk pembelajaran bahasa Indonesia dengan gaya belajar VARK, seperti penggunaan media pembelajaran video berupa film. Siswa dapat melihat, mendengar, dan merasakan apa yang ada dalam video tersebut. Setelah selesai memperhatikan film tersebut maka dalam diri siswa timbul hal-hal yang dapat didiskusikan bersama teman lainnnya, baik karena unsur instriknya, durasi waktunya, serta ketertarikan pada film tersebut atau sebaliknya.

Belajar melibatkan proses psikologis dan proses biologis yang terjadi dalam pemikran. Penelitan (Espinoza-Poves, Miranda-Vilchez, \& Chafloque-Céspedes, 2019) diungkapkan bahwa ketika guru memberikan materi, memberikan tugas individu ataupun kelompok, diskusi, dan melakukan evaluasi. Hasil dari evaluasi akan menunjukkan tidak semua siswa mencapai pembelajaran yang memuaskan. Hal ini bukan karena kemampuan siswa kurang tetapi ada gaya belajar yang berbeda di dalam proses pembelajaran. Guru harus menciptakan suasana belajar yang menyenangkan dan membangkitkan motivasi siswa dalam bersaing meraih prestasi. Pemilihan kegiatan dengan mengembangkan banyak kegiatan seperti diskusi yang dipilih guru menjadi hal yang tepat untuk meningkatkan keaktifan siswa di kelas. Diskusi berarti melibatkan siswa untuk berintaksi secara fisik (Davidson, 2019). Adanya diskusi maka siswa dapat menghargai pendapat orang lain serta dapat 
menjadi stimulus bagi siswa lain yang belum berpendapat.

Berdasarkan hal di atas maka dapat simpulkan bahwa gaya belajar dapat meningkatkan keaktifan siswa dalam pembelajaran bahasa Indonesia. Hal ini dikarenakan guru memahami gaya belajar setiap siswa, selanjutnya guru memilih dan menentukan gaya mengajarnya untuk memenuhi gaya belajar siswa agar tercapai tujuan pembelajaran. Inilah yang dapat memberikan berbagai kemngkinan siswa memiliki kesempatan yang sama untuk belajar sehingga akan menyadari kekuatan dan kelemahan dirinya sehingga secara positif akan dapat memengaruhi sikap.

\section{KESIMPULAN DAN SARAN}

Siswa sebagai pemelajar memiliki gaya belajar yang berbeda dari siswa lainnya. masing-masing siswa menyukai dan memilih gaya belajar sesuai dengan karakteristiknya. Gaya belajar yang dapat digunakan sebagai ciri khas siswa dalam belajar ini perlu didukung oleh guru. Setiap siswa memiliki karakteristik yang harus diperhatikan guru untuk mendesain pembelajaran yang akan dikelola yaitu gaya belajar. Dalam kegiatan pembelajran terdapat unsur fisik dan mental. Penguasaan materi ajar di sekolah yang dapat dicapai dengan baik oleh siswa tentu sebagai hasil dari mewujudkan suasana belajar yang menyenangkan, yakni dengan gaya belajar yang tepat. Adanya gaya belajar tersebut maka dapat meningkatkan hasil belajar pembelajaran bahasa Indonesia.

Empat keterampilan berbahasa menjadi kebutuhan dan harus dikuasai oleh siswa. Siswa melakukan belajar artinya ada perubahan dari segi kognitif, afektif, dan psikomotoriknya. Hal itu dapat diperoleh melalui panca indera yang dimiliki. Guru harus menggunakan gaya pengajaran yang sesuai dengan kondisi lingkungan dan karakteristik siswa. Dalam pembelajaran bahasa Indonesia guru dapat memilih materi sastra atau materi yang lain yang secara tepat sesuai tujuan pembelajaran dan menggunakan media visual, audio, atau audio visual dalam pembelajaan yang kesemuanya itu melibatkan gaya belajar VARK yaitu visual (penglihatan), auditory (pendengaran), dan kinesthetic (gerak dan rasa).

\section{DAFTAR PUSTAKA}

Alnujaidi, S. (2018). The Difference between EFL Students' Preferred Learning Styles and EFL Teachers' Preferred Teaching Styles in Saudi Arabia. English Language Teaching, 12(1), 90. https://doi.org/10.5539/elt.v12n1p90

Aydin, B. (2015). Examination of the Relationship between Eighth Grade Students' Learning Styles and Attitudes towards Mathematics. Journal of Education and Training Studies, 4(2), 


\section{4-130.}

https://doi.org/10.11114/jets.v4i2.1162

Çınar, I. (2019). An Examination of Student Club Activities from the Perspective of School Principals and Teachers. World Journal of Education, 9(4), 123. https://doi.org/10.5430/wje.v9n4p123

Davidson, S. (2019). Artistic Classroom Activities: What Skills Can Students Learn? Journal for Learning through the Arts: A Research Journal on Arts Integration in Schools and Communities, 14(1).

https://doi.org/10.21977/d914136830

Dorça, F. A., Araújo, R. D., de Carvalho, V. C., Resende, D. T., \& Cattelan, R. G. (2016). An automatic and dynamic approach for personalized recommendation of learning objects considering students learning styles: An experimental analysis. Informatics in Education, 15(3), 45-62. https://doi.org/10.15388/infedu.2016.03

Entwistle, N. (1998). Stylies Learning and Teaching. New York: David Fulton Publisher.

Espinoza-Poves, J., Miranda-Vilchez, W., \& Chafloque-Céspedes, R. (2019). The Vark Learning Styles among University Students of Business Schools. Journal of Educational Psychology - Propositos y Representaciones, 7(2), 401-415.

Ezzeldin, S. M. Y. (2017). The Effectiness of Using Graphic Organizers in Development of Achievement, Reduction of Cognitive Load Associated With Solving Algorithm Problems in Analytical Chemistry and Favored Learning Styles among Female Secondary School Students in Saudi Arabia T. 41(2).

Felming, N. (2001). Teaching and Learning Styles: VARK Strategies. New Zealand:
Neil D Fleming.

García, J. (2007). El modelo Vark intrumento diseñado para identificar estilos de enseñanza - aprendizaje Traducción del documento diseñado por Neil Fleming. Unviesridad Pedagógica de Durango, 6(enero), 86-90. Retrieved from https://dialnet.unirioja.es/descarga/artic ulo/2293085.pdf

Kolb, D. A. (2015). Experriential Learning: Experience The Source of Learning and Development. USA: Person Education, Inc.

Medicine, N. R. C. and the I. of. (2004). Engaging Schools. Washington, DC: The National Academy of Sciences.

NA, W. (2013). Manajemen Kelas Teori dan Aplikasi utuk Menciptakan Kelas Kondusif. Yogyakarta: Ar-Ruzz Media.

Siki, F. (2019). Problematika Strategi Pembelajaran Bahasa Indonesia. Jurnal Pendidikan Bahasa Dan Sastra Indonesia, 4(2), 71-76. https://doi.org/10.32938/jbi.v4i2.213

Silverman, W. L., \& Forum, L. (1992). Learning and Teaching Styles. 78(1979), $1-10$.

Tarnisih, E. (2019). BAHTERA INDONESIA: Jurnal Penelitian Pendidikan Bahasa dan Sastra Indonesia. 4(2), 130-148.

Vinyamata, E. (2011). The Neuro-Linguistic Programming Approach to Conflict Resolution, Negotiation and Change. Journal of Conflictology, (1), 8. https://doi.org/10.7238/joc.v2i1.1085

Wijaya, R. S. (2015). BELAJAR SISWA : Rasman Sastra Wijaya. Jurnal Penelitian Tindakan Bimbingan dan Konseling, 1(3), 40-45. 